\author{
Коныгина Маргарита Николаевна
}

\title{
ИЗУЧЕНИЕ ОТНОШЕНИЯ МАГИСТРАНТОВ К НАУЧНО-ИССЛЕДОВАТЕЛЬСКОЙ ДЕЯТЕЛЬНОСТИ В ПРОЦЕССЕ ПРОФЕССИОНАЛЬНОЙ ПОДГОТОВКИ
}

В статье раскрывается значимость изучения мнений магистрантов о современной науке и ее роли в профессионально-личностном становлении будущих магистров как высококвалифицированиых профессионалов; приводятся теоретические обоснования проблемы соотночения научно-исследовательской деятельности и профессионально-личностного развития ее субъекта; рассиатриваются организационные основы построения образовательного процесса, ориентированного на подготовку обучалочихся в вузе к научно-исследовательской деятельности; обозначаются направления развития системы подготовки будущих магистров к выполнению профессиональнытх задач посредством решения научной проблемы и использования собственных научных достижений.

Ключевые слова: наука, научно-исследовательская деятельность, научно-исследовательская деятельность магистрантов в вузе, организация научно-исследовательской деятельности обучающихся в вузе.

\section{Margarita Konygina \\ A STUDY OF THE ATTITUDE OF UNDERGRADUATES TO RESEARCH ACTIVITIES IN THE TRAINING PROCESS}

The article reveals the importance of studying the views of undergraduates on modern science and its role in the professional and personal development of future masters as highly qualified professionals; provides theoretical justification for the problem of the ratio of research activities and professional and personal development of its subject; discusses the organizational foundations of the educational process, focused on the preparation of students; the directions of development of the system of training future masters to perform professional tasks by solving scientific problems and using their own scientific achievements.

Key words: science, research activity, research activity of undergraduates at the University, organization of research activities of students at the University.

Bведениe /Introduction. В XXI веке правительство Российской Федерации отнесло науку и образование к стратегическим национальным приоритетам страны, вследствие чего предпринимаются необходимые меры по вопросам инновационных и интеграционных процессов в сфере образования и науки. В соответствии с этим 15 мая 2018 года Президент России подписал указ «О структуре федеральных органов исполнительной власти», преобразовав Министерство образования и науки Российской Федерации в Министерство просвещения Российской Федерации и Министерство науки и высшего образования Российской Федерации.

Реорганизация системы управления высшим образованием и наукой задает мощный импульс в их интеграции. Общая координация научной и образовательной деятельности в высшей школе способствует развитию системы подготовки научных кадров через магистратуру, аспирантуру и докторантуру путем использования современных научных достижений в образовательной практике, гармонизации учебной и научно-исследовательской деятельности в вузе.

Развитие системы многоуровневого образования и подготовки научных кадров предполагает предварительное изучение реального состояния организации научно-исследовательской деятельности в высших учебных заведениях, включающее в том числе и исследование мнений обучающихся в вузе о значимости науки и научно-исследовательской деятельности в процессе их личностного и профессионального становления. 
Значительный вклад в разработку проблематики науки как социального института, практики познания и преобразования действительности и самого человека, роли научной деятельности в личностном развитии ее субъекта внесен работами В. А. Бажанова, Н. Ф. Басовой, Е. В. Бережновой, И. Ю. Даниловой, И. А. Зимней, В. В. Краевского и др.

Научно-исследовательская деятельность рассматривается как:

- познавательная, интеллектуальная, творческая деятельность, направленная на получение и применение новых знаний, создание нового продукта, развитие новых взглядов на социальные явления и процессы, формирование нового направления в общественном мировоззрении и др.;

- структурный компонент различных видов профессиональной деятельности выпускников магистратуры, аспирантуры, докторантуры и один из базовых элементов многоуровневой системы подготовки в вузе;

- фактор личностного становления субъекта научно-исследовательской деятельности, формирования его мировоззренческих позиций, ценностных ориентаций, мотивации на дальнейшее профессионально-личностное развитие, интеллектуальное и творческое становление и самосовершенствование в научной сфере, практике применения научных достижений и результатов собственных научных исследований $[1 ; 2 ; 3 ; 4 ; 6 ; 7$ и др.].

Магистратура - первая ступень подготовки научных кадров (магистратура, аспирантура, докторантура). В двухуровневой системе высшего профессионального образования, интенсивно развивающегося в российском образовательном пространстве, магистратура относится ко второму уровню: в ходе обучения осуществляется подготовка выпускников, способных к решению наиболее сложных задач профессиональной деятельности, а также к научно-исследовательской деятельности в конкретной научной и профессиональной сфере. Содержание и направленность научно-исследовательской деятельности будущих магистров задаются проблематикой профессиональной деятельности.

В результате освоения программы магистратуры выпускники должны решать различные задачи, среди которых к наиболее общим (в рамках научно-исследовательской деятельности) относятся: организация и проведение прикладных / фундаментальных исследований в конкретной научной сфере; разработка предложений по использованию информационных технологий в целях повышения эффективности профессиональной деятельности; обработка социальной, демографической, экономической и др. информации с привлечением широкого груга источников на основе использования современных информационных технологий, средств вычислительной техники, коммуникаций и связи; подготовка обзоров, аннотаций, отчетов, аналитических записок, профессиональных публикаций, информационных материалов по результатам исследовательских работ и др. [8; 9].

Одно из главных требований к современным выпускникам магистратуры - высокий научный уровень магистрантов, умение самостоятельно проводить исследования и применять их результаты в решении учебных задач, а таюже реализовывать собственные научные достижения на практике.

Формирование опыта научного познания, по мнению Л. Г. Пак, определяет становление иного качества выпускников вузов - исследователей социальной реальности, освоивших большой объем знаний информационного общества, что позволяет им самостоятельно выдвигать новые идеи, конструировать новую социальную реальность в соответствии с прогрессивным влиянием инновационного социума [6].

По мнению современных ученых (В. В. Балашов, Г. В. Лагунов, Е. В. Пискунова и др.), ценностная сущность научно-исследовательской деятельности как систематизирующего компонента образовательного процесса в вузе заключается в том, что обучающиеся выступают субъектами педагогического процесса с присущими им мировоззренческими установками, потребностями, мотивами, идеалами, профессиональными и личностными предпочтениями $[5 ; 7]$. 
Такое понимание ценностной сущности научно-исследовательской деятельности является важнейшим условием построения образовательного процесса, направленного на личностное и профессиональное развитие магистрантов, формирование научной позиции выпускников, ценностного отношения к научным знаниям и их реализации в профессиональной деятельности.

В последние годы в ряде исследований (В. В. Балашова, Г. В. Лагунов, И. В Малюгина, В. М. Шейко и др.) раскрываются организационные основы научно-исследовательской деятельности (НИД) в вузе.

НИД изначально встраивается в учебный процесс, где данный вид деятельности определяется учебными планами, стандартами и проводится в рамках лекций, семинаров, практик и других видов учебной деятельности. Такая деятельность должна выполняться студентами под методическим руководством преподавателей или научных руководителей из числа практикующих специалистов. Базовая цель при этом - организация научно-исследовательской деятельности обучающихся в процессе их профессиональной подготовки и выполнения различных видов учебной деятельности, направленной на освоение будущей профессии.

НИД дополняет учебный процесс, когда обучающиеся работают над научными исследованиями, включенными в планы научно-исследовательской работы кафедры (в пределах основного рабочего времени), а не определенными стандартами, планами и учебными программами подготовки студентов. Такая организация НИД требует достаточного уровня мотивационной готовности обучающихся к выполнению научных исследований. Цель - индивидуализация процесса обучения посредством научно-исследовательской деятельности, вынесенной за рамки учебного процесса в вузе.

НИД предполагает участие в бюджетных и внебюджетных научных исследованиях и организуется параллельно учебному процессу. Такая организационная основа НИД предполагает мотивированность обучающихся к выполнению конкретной научной проблемы и достаточную сформированность умений самостоятельно организовывать и проводить научные исследования. Цель - повышение уровня научной квалификации и получение навыка работы в научных коллективах и организациях $[5 ; 10]$.

Соотношение учебного процесса и научно-исследовательской деятельности в магистратуре определяется стандартом конкретного направления подготовки. В соответствии с современными стандартами, подготовка обучающихся в магистратуре включает выполнение всех видов учебной деятельности (лекции, семинары, практика, самостоятельная работа и др.), направленной на решение учебных задач и научных проблем в определенной сфере профессиональной деятельности [8; 9]. Организация НИД в вузе, отражающая направленность на формирование навыков решения учебных задач посредством реализации собственных научных достижений (результаты теоретического анализа и опытно-экспериментального исследования научной проблемы конкретной профессиональной сферы и др.), становится для будущих магистров основой личностного принятия ценностей науки, осознания значимости научно-исследовательской деятельности в их профессиональном становлении.

Актуализируя изученные мнения магистрантов о значимости научно-исследовательской деятельности в их профессионально-личностном развитии, мы руководствовались следующими рассуждениями:

- ценностная сущность науки заключается в том, что она направлена на создание объективных знаний и преобразование социальной реальности и самого человека как члена обшества (профессионального сообщества);

- $\quad$ научные знания лежат в основе формирования общественного мировоззрения, личной позиции человека, системы его ценностей (профессиональных ценностей);

- научно-исследовательская деятельность определяет личностное развитие ученого, его ценностные ориентации и профессиональную позицию; 
- профессиональная деятельность магистра включает научно-исследовательскую деятельность как самостоятельную практику, направленную на решение профессиональных задач средством внедрения прогрессивных научных открытий и собственных научных достижений;

- научно-исследовательская деятельность магистранта выступает детерминантом его личностного и профессионального развития, формирования профессиональной позиции, развития профессионально-ценностных ориентаций;

- научно-исследовательская деятельность магистранта организуется посредством не только выполнения основных видов учебной деятельности в вузе, но и привлечения обучающихся к работе над грантами, участию в решении научно-исследовательской деятельности кафедры, вуза и др.

Указанные рассуждения легли в основу проведенного эмпирического исследования с целью изучения мнений магистрантов Института образования и социальных наук СКФУ о роли научно-исследовательской деятельности в личностном и профессиональном становлении будущих профессионалов.

Maтериалы и методы / Materials and methods. В соответствии с поставленными целями исследования был организован процесс изучения отношения к науке и научно-исследовательской деятельности обучающихся в магистратуре. Общее количество испытуемых - 120 человек. Лонгитюдное исследование проводилось в течение 2 лет. В эксперименте приняли участие магистранты направлений подготовки 39.04.03 Организация работы с молодежью, 44.04.01 Педагогическое образование.

Для решения поставленных задач нами была разработана анкета, направленная на изучение представления магистранта о науке и отношения к ней, выявление значимости научно-исследовательской деятельности в профессионально-личностном становлении магистра. Анкета содержала как открытые, так и закрытые вопросы.

В процессе разработки проблемы было высказано предположение о том, что отношение к науке как двигателю общественного прогресса не утрачивает своего значения среди студенческой молодежи. Однако при понимании значимости научного прогресса и роли науки в общественном развитии, формировании социальных практик обучающиеся в вузе не всегда осознают значимость научно-исследовательской деятельности в их личностном и профессиональном развитии. Выявленные в ходе опроса проблемные зоны в системе подготовки магистрантов, станут основой для формирования новых подходов к организации научно-исследовательской деятельности в вузе.

Результаты и обсужсдение / Results and discussion. Первые вопросы анкеты были посвящены изучению мнений магистрантов о роли науки в обществе. Мы предложили респондентам уже готовые варианты ответов, отражающих понимание роли науки по характеру ее преобразовательной силы. Обучающиеся в магистратуре могли выбирать несколько позиций из предложенных. $65 \%$ магистрантов указали на возможности науки в систематизации знаний в различных областях; 73 \% опрошенных считают науку двигателем общественного прогресса; 72 \% респондентов обозначили роль научных открытий в создании и внедрении инновационных проектов, программ, технологий, в том числе и образовательных технологий. С трактовкой науки как составляющей части социальной жизни согласились $75 \%$ анкетируемых.

Далее выяснялась роль научно-исследовательской деятельности в профессиональной подготовке магистров: из общего числа опрошенных магистрантов 77 \% считают НИД важной частью обучения по магистерским программам. Следует отметить, что в этой категории доминируют ответы о научно-исследовательской деятельности как средстве получения «бонуса» от преподавателей. Так, 51 \% участников отметили утверждение о том, что «достижения в исследовательской деятельности магистранта позволяют получать определенные бонусы от преподавателей»; 31 \% опрошенных - что «процесс обучения связан с наукой, так как основы науки определяют образо- 
вательный процесс и содержание учебных дисциплин». Лишь $18 \%$ респондентов ответили, что научные достижения и опыт научно-исследовательской деятельности способствуют их личностному развитию, профессиональному становлению и совершенствованию.

Опрос показал, что магистранты участвуют в отдельных видах НИД: выполнение курсовых работы ( $100 \%$ ), работа в научном кружке (11\% из всего количества опрошенных), участие в работе научно-практических конференций (58 \%), участие в написании грантов кафедры (5\%) и др.

Большая часть магистрантов положительно относится к решению исследовательских задач при выполнении курсовых работ (56 \%) и различных видов практики (43\%); 33 \% считают интересной формой исследовательской работы участие в научных конференциях, форумах, конкурсах; $44 \%$ опрошенных проявляют интерес к работе научных кружков, но только $9 \%$ из них в научных кружках занимаются.

Всего $25 \%$ респондентов ответили, что привлекательным видом научно-исследовательской деятельности является выполнение выпускной квалификационной работы. При этом необходимо отметить, что практически все (95\% из $100 \%$ ) отнесли этот вид НИД к наиболее трудоемкому, занимающему много времени и требующему определенной подготовки. В ходе опроса 75 \% магистрантов высказались, что исследовательская деятельность при выполнении квалификационной работы вызывает затруднение; 24 \% ответили, что этот вид НИР неинтересен и вряд ли пригодится в их профессиональной деятельности.

К участию в работе научных обществ, олимпиадах и других более сложных видах НИР (грантовые проекты, работа над проблемой кафедры, вуза и др.) привлечена лишь небольшая часть магистрантов $-8 \%$. Это связано с недостатком опыта выполнения различных видов НИД, сложностью научных проблем, а также неразработанностью технологии привлечения обучающихся к научно-исследовательской деятельности, выходящей за рамки образовательного процесса.

Положительным является тот факт, что 78 \% магистрантов имеют публикации в сборниках научно-практических конференций различного уровня. 68 \% магистрантов, имеющих публикации, выразили мнение о том, что публикационная активность обучающихся позволяет им получить дополнительные бонусы от преподавателей, в том числе и при защите выпускной квалификационной работы. И лишь $22 \%$ из общего числа магистрантов, имеющих собственные публикации, ответили, что результаты их научных исследований могут пригодится в будущей профессиональной деятельности.

Заключение / Conclusion. Теория и практика организации научно-исследовательской деятельности в вузе, а также анализ мнений магистрантов об этом виде деятельности в учебном процессе позволяют заключить, что научно-исследовательская деятельность влияет на профессионально-личностное развитие магистрантов, формирование их научной и профессиональной позиции, ценностного отношения к науке, ее роли и значении в общественном развитии.

Несмотря на то что научно-исследовательская деятельность магистрантов разнообразна как по направленности, так и по содержанию, формам и организационной структуре, для обучающихся в магистратуре этот процесс должен быть неразрывно связан с выполнением всех видов учебной деятельности в единстве с решением научных проблем и исследовательских задач в конкретной профессиональной сфере. Педагогический процесс должен включать формы и методы вовлечения обучающихся в научно-исследовательскую деятельность, вынесенную за рамки учебной работы (такие как участие в бюджетных и внебюджетных научных исследованиях (грантах), выполнении научных исследований кафедры и / или вуза, организованных параллельно учебному процессу), повышает уровень научной квалификации магистранта, способствует развитию навыков работы в научных коллективах (организациях) и создает предпосылки для последующего обучения магистра в аспирантуре, докторантуре.

Такая подготовка обеспечит направленность на формирование высококвалифицированных профессионалов как субъектов научно-исследовательской деятельности в конкретной научной и профессиональной сферах. 


\section{ЛИТЕРАТУРА И ИНТЕРНЕТ-РЕСУРСЫ}

1. Бажанов В. А. Наука как самопознающая система. Казань: КГУ, 1991.

2. Басов Н. Ф. Научно-исследовательская деятельность как средство формирования профессиональной компетентности будущих бакалавров социальной работы // Вестник Костромского государственного университета им. Н. А. Некрасова. 2011. № 1. С. 55-59.

3. Бережнова Е. В., Краевский В. В. Основы учебно-исследовательской деятельности студентов. М.: Академия, 2005. $128 \mathrm{c}$.

4. Зимняя И. А. Исследовательская работа как специфический вид человеческой деятельности. Москва; Ижевск: Исследовательский центр проблем качества подготовки специалистов; Удмуртский государственный университет, 2001.

5. Организация научно-исследовательской деятельности студентов в вузах России: монография: в 3 ч. / В. В. Балашов, Г. В. Лагунов, И. В. Малюгина, В. В. Масленников [и др.] / под общ. ред. В. В. Балашова. М., 2002.

6. Пак Л. Г. Социально ориентированная деятельность студента вуза: от идеи к реализации: монография. Оренбург: Оренбургский институт экономики и культуры (Institut fur interkulturelle Kommunikation), $2013.312 \mathrm{c}$.

7. Пискунова Е. В. Исследовательская деятельность обучающихся: бакалавриат, магистратура, аспирантура // Педагогика. 2010. № 7. С. 8-65.

8. Об утверждении федерального государственного образовательного стандарта высшего образования по направлению подготовки 39.04.03 Организация работы с молодежью (уровень магистратуры): Приказ Министерства образования и социальных наук Российской Федерации от 23.09.2015 № 1046. [Электронный ресурс]. Доступ из портала ФГОС ВО.

9. Об утверждении федерального государственного образовательного стандарта высшего образования по направлению подготовки 44.04.01 Педагогическое образование (уровень магистратуры): Приказ Министерства образования и социальных наук Российской Федерации от 21.11.2014 № 1505 [Электронный ресурс]. Доступ из портала ФГОС ВО.

10. Шейко В. М., Кушнаренко Н. М. Організація та методика науково-дослідницької діяльності: [підручник]. 4-те вид., випр.і доп. К.: Знання, 2004. 307 с.

\section{REFERENCES AND INTERNET RESOURCES}

1. Bazhanov V.A. Nauka kak samopoznayushchaya sistema (Science as a self-aware system). Kazan': KGU, 1991.

2. Basov N. F. Nauchno-issledovatel'skaya deyatel'nost' kak sredstvo formirovaniya professional'noj kompetentnosti budushchih bakalavrov social'noj raboty (Research activity as a means of formation of professional competence of future bachelors of social work) // Vestnik Kostromskogo gosudarstvennogo universiteta im. ‥ A. Nekrasova. 2011. № 1. Pp. 55-59.

3. Berezhnova E. V., Kraevskij V. V. Osnovy uchebno-issledovatel'skoj deyatel'nosti studentov (Basics of educational and research activities of students). M.: Akademiya, 2005. $128 \mathrm{p}$.

4. Zimnyaya I. A. Issledovatel'skaya rabota kak specificheskij vid chelovecheskoj deyatel'nosti (Research work as a specific type of human activity). Moskva; Izhevsk: Issledovatel'skij centr problem kachestva podgotovki specialistov; Udmurtskij gosudarstvennyj universitet, 2001.

5. Organizaciya nauchno-issledovatel'skoj deyatel'nosti studentov v vuzah Rossii (The organization of scientific-research activity of students in universities of Russia): monografiya: v $3 \mathrm{ch}$. / V. V. Balashov, G. V. Lagunov, I. V. Malyugina, V. V. Maslennikov [i dr.] / pod obshch. red. V. V. Balashova. M., 2002.

6. Pak L. G. Social'no orientirovannaya deyatel'nost' studenta vuza: ot idei k realizacii: monografiya (Socially oriented activity of a University student: from idea to implementation): monografiya. Orenburg: Orenburgskij institut ehkonomiki i kul'tury (Institut fur interkulturelle Kommunikation), 2013. 312 p.

7. Piskunova E. V. Issledovatel'skaya deyatel'nost' obuchayushchihsya: bakalavriat, magistratura, aspirantura (Research activities of students: bachelor, master, postgraduate) // Pedagogika. 2010. № 7. Pp. 8-65. 
8. Ob utverzhdenii federal'nogo gosudarstvennogo obrazovatel'nogo standarta vysshego obrazovaniya po napravleniyu podgotovki 39.04.03 Organizaciya raboty s molodezh'yu (uroven' magistratury) (About the approval of the Federal state educational standard of the higher education in the direction of preparation 39.04 .03 the Organization of work with youth (level of the magistracy)): Prikaz Ministerstva obrazovaniya i social'nyh nauk Rossijskoj Federacii ot 23.09.2015 № 1046. [EHlektronnyj resurs]. Dostup iz portala FGOS VO.

9. Ob utverzhdenii federal'nogo gosudarstvennogo obrazovatel'nogo standarta vysshego obrazovaniya po napravleniyu podgotovki 44.04.01 Pedagogicheskoe obrazovanie (uroven' magistratury) (About the approval of the Federal state educational standard of the higher education in the direction of preparation 44.04.01 Teacher education (master's degree level)): Prikaz Ministerstva obrazovaniya i social'nyh nauk Rossijskoj Federacii ot 21.11.2014. № 1505. [EHlektronnyj resurs]. Dostup iz portala Federal'nyh gosudarstvennyh obrazovatel'nyh standartov vysshego obrazovaniya.

10. Shejko V. M., Kushnarenko N. M. Organizaciya ta metody'ka naukovo-doslidny 'cz'koyi diyal nosti (Organization and methodology of research activities): [pidruchny'k]. 4-te vy'd., vy' pr.i dop. K.: Znannya, 2004. $307 \mathrm{p}$.

\section{СВЕДЕНИЯ ОБ АВТОРАХ}

Коныгина Маргарита Николаевна, кандидат педагогических наук, доцент кафедры социальных технологий института образования и социальных наук ФГАОУ ВО Северо-Кавказский федеральный университет. E-mail: m-konygina $@$ yandex.ru

\section{INFORMATION ABOUT AUTHOR}

Konygina Margarita, Candidate of Pedagogical Sciences, associate Professor of the Department of social technologies of the Institute of education and social Sciences of the North-Caucasus Federal University. E-mail m-konygina $@$ yandex.ru 